\title{
Two new species of Geejayessia (Hypocreales) from Asia as evidenced by morphology and multi-gene analyses
}

\author{
Zhao-Qing Zeng', Wen-Ying Zhuang' \\ I State Key Laboratory of Mycology, Institute of Microbiology, Chinese Academy of Sciences, Beijing 100101, \\ PR China
}

Corresponding authors: Zhao-Qing Zeng (zengzq@im.ac.cn); Wen-Ying Zhuang (zhuangwy@im.ac.cn)

Academic editor: George Mugambi | Received 20 June 2018 | Accepted 9 October 2018 | Published 6 November 2018

Citation: Zeng Z-Q, Zhuang W-Y (2018) Two new species of Geejayessia (Hypocreales) from Asia as evidenced by morphology and multi-gene analyses. MycoKeys 42: 7-19. https://doi.org/10.3897/mycokeys.42.27664

\begin{abstract}
Two new species of Geejayessia are introduced, based on materials collected from central China. Geejayessia clavata sp. nov. is characterised by gregarious, red brownish to dark red, oval-subglobose to globose perithecia that are formed on a basal stroma; (4-7-)8-spored cylindrical asci; ellipsoidal or rarely broadly ellipsoidal, uniseptate, smooth or finely verruculose ascospores; clavate, aseptate microconidia and absence of macroconidia. Geejayessia sinica sp. nov. is characterised by red to bright red, pyriform, subglobose to globose, perithecia on a basal stroma, collapsing laterally when dry; subcylindrical to clavate asci with a rounded apex; ellipsoidal, uniseptate ascospores; and falcate, multiseptate macroconidia with an arcuate tip. Morphological distinctions of the new species from the related fungi are discussed. This is the first report of Geejayessia from Asia.
\end{abstract}

\section{Keywords}

Cosmospora-like fungi, Nectriaceae, Systematic, Taxonomy

\section{Introduction}

Some fusarium-like species having gregarious, multicoloured, broadly ampulliform shortnecked or broadly ellipsoidal perithecia were previously placed in Cosmospora Rabenh. and Nectria (Fr.) Fr. (Booth 1959; Samuels and Rogerson 1984; Nirenberg and Samuels 2000) until the genus Geejayessia Schroers, Gräfenhan \& Seifert, typified by G. cicatricum (Berk.) Schroers, was introduced (Schroers et al. 2011). The genus is characterised 
by prosenchymatous stromata erumpent through substrates, caespitose, broadly pyriform, pale orange, brownish to reddish-orange, bright red to black perithecia, reacting to potassium hydroxide $(\mathrm{KOH})$ and lactic acid (LA); cylindrical or clavate asci with eight ascospores; broadly ellipsoidal to ellipsoidal ascospores that are uniseptate, slightly constricted at the septum, hyaline or pale brown to yellowish-brown, smooth or verruculose at maturity; and multiseptate, slightly curved macroconidia with conspicuous pedicellate foot cell (Schroers et al. 2011; Lombard et al. 2015). Members of Geejayessia exhibit host specificity and mainly occur on Buxus spp., Celtis occidentalis and Staphylea trifolia and were reported only from Europe, North America and Oceania (Samuels and Rogerson 1984; Nirenberg and Samuels 2000; Schroers et al. 2011).

In our examinations of nectriaceous collections from central China, two cosmosporalike fungi were encountered. Judging by perithecial gross morphology, anatomic structures and culture characteristics, they represented two previously undescribed species of Geejayessia. Their taxonomic placements were confirmed by multigene phylogenetic analyses. Distinctions between the new species and their closely related fungi are discussed.

\section{Materials and methods}

\section{Sampling and morphological studies}

Specimens were collected from Shennongjia National Nature Reserve and Longyuwan National Forest Park and were deposited in the Herbarium Mycologicum Academiae Sinicae (HMAS). Methods used by Luo and Zhuang (2010) and Schroers et al. (2011) were generally followed for morphological observations. The test for colour changes of the perithecial wall was made with $3 \% \mathrm{KOH}$ and $100 \%$ LA. To observe internal and microscopic characteristics of the perithecial wall, longitudinal sections through ascomata were made with a freezing microtome (YD-1508-III, Jinhua, China) at a thickness of 6-8 $\mu \mathrm{m}$. Microscopic examinations and measurements were taken from longitudinal sections and squash mounts in lactophenol cotton blue solution using an Olympus BH-2 microscope (Tokyo, Japan). Photographs were taken with a Leica DFC450 digital camera (Wetzlar, Germany) attached to a Leica M125 stereomicroscope (Milton Keynes, UK) for gross morphology and a Zeiss AxioCam MRc 5 digital camera (Jena, Germany) attached to a Zeiss Axio Imager A2 microscope (Göttingen, Germany) for anatomical structures. Measurements of individual structures were based on 30 units, except when otherwise noted. Cultures were obtained by single ascospore isolation from fresh ascomata. To determine colony features, isolates were grown on cornmeal dextrose agar [CMD, 4\% (w/v) cornmeal $+2 \%(\mathrm{w} / \mathrm{v})$ dextrose $+2 \%(\mathrm{w} / \mathrm{v})$ agar], potato dextrose agar [PDA, 20\% (w/v) potato $+2 \%(\mathrm{w} / \mathrm{v})$ dextrose $+2 \%(\mathrm{w} / \mathrm{v})$ agar] and synthetic nutrient-poor agar (SNA; Nirenberg 1976) in $90 \mathrm{~mm}$ plastic dishes at $25^{\circ} \mathrm{C}$ for $7 \mathrm{~d}$. For the observation of conidiophores, macroconidia and microconidia, cultures were grown on SNA at $25^{\circ} \mathrm{C}$ with alternating periods of light/darkness $(12 \mathrm{~h} / 12 \mathrm{~h})$. Colony growth rates were measured after $7 \mathrm{~d}$. 
Table I. List of species, herbarium/strain numbers and GenBank accession numbers of materials used in this study.

\begin{tabular}{|c|c|c|c|c|}
\hline \multirow{2}{*}{ Species } & \multirow{2}{*}{$\begin{array}{c}\text { Herbarium/strain } \\
\text { numbers }\end{array}$} & \multicolumn{3}{|c|}{ GenBank accession numbers } \\
\hline & & acl1 & ITS & $r p b 2$ \\
\hline Albonectria albosuccinea (Pat.) Rossman \& Samuels & BBA 64502 & HQ897837 & HQ897788 & HQ897699 \\
\hline A. rigidiuscula (Berk. \& Broome) Rossman \& Samuels & CBS 122570 & HQ897896 & HQ897815 & HQ897760 \\
\hline Cyanonectria buxi (Fuckel) Schroers, Gräfenhan \& Seifert & CBS 125554 & HM626629 & HM626660 & HM626688 \\
\hline C. cyanostoma (Sacc. \& Flageolet) Samuels \& P. Chaverri & CBS 101734 & HQ897895 & FJ474076 & HQ897759 \\
\hline Dialonectria episphaeria (Tode) Cooke & CBS 125494 & HQ897892 & HQ897811 & HQ897756 \\
\hline D. ullevolea Seifert \& Gräfenhan & CBS 125493 & HQ897918 & KM231821 & HQ897782 \\
\hline Fusarium sambucinum Fuckel & CBS 14695 & KM231015 & KM231813 & KM232381 \\
\hline F. sublunatum Reinking & BBA 62431 & HM897916 & HQ897830 & HQ897780 \\
\hline Fusicolla acetilerea (Tubaki, C. Booth \& T. Harada) Gräfenhan \& Seifert & BBA 63789 & HQ897839 & HQ897790 & HQ897701 \\
\hline F. matuoi (Hosoya \& Tubaki) Gräfenhan \& Seifert & CBS 58178 & HQ897858 & KM231822 & HQ897720 \\
\hline Geejayessia atrofusca (Schwein.) Schroers \& Gräfenhan & CBS 125505 & HM626628 & HM626659 & HM626682 \\
\hline G. celtidicola Gräfenhan \& Schroers & CBS 125502 & HM626625 & HM626657 & HM626685 \\
\hline G. cicatricum (Berk.) Schroers & CBS 125552 & HQ728171 & HQ728145 & HQ728153 \\
\hline G. desmazieri (De Not. \& Becc.) Schroers & CBS 125507 & HM626633 & HM626651 & HM626675 \\
\hline G. clavata Z.Q. Zeng \& W.Y. Zhuang & HMAS 248725 & KY873305 & KY873307 & KY873309 \\
\hline G. sinica Z.Q. Zeng \& W.Y. Zhuang & HMA S248726 & KY873306 & KY873308 & KY873310 \\
\hline G. zealandica (Cooke) Schroers & CBS 11193 & HM626626 & HM626658 & HM626684 \\
\hline Macroconia leptosphaeriae (Niessl) Gräfenhan \& Schroers & CBS 100001 & HQ897891 & HQ897810 & HQ897755 \\
\hline M. papilionacearum (Seaver) Gräfenhan \& Seifert & CBS 125495 & HQ897912 & HQ897826 & HQ897776 \\
\hline Microcera coccophila Desm. & CBS 31034 & HQ897843 & HQ897794 & HQ897705 \\
\hline M. diploa (Berk. \& M.A. Curtis) Gräfenhan \& Seifert & BBA 62173 & HQ897899 & HQ897817 & HQ897763 \\
\hline Nalanthamala psidii (Sawada \& Kuros.) Schroers \& M.J. Wingf. & CBS 116952 & KM231073 & AY864836 & KM232401 \\
\hline Neocosmospora ramosa (Bat. \& H. Maia) L. Lombard \& Crous & CBS 50963 & KM231004 & KM231802 & KM232369 \\
\hline N. vasinfecta E.F. Sm. & CBS 32554 & KM231005 & KM231803 & KM232370 \\
\hline Stylonectria applanata Höhn. & CBS 125489 & HQ897875 & HQ897805 & HQ897739 \\
\hline S. purtonii (Grev.) Gräfenhan & DAOM 235818 & HQ897919 & HQ897831 & HQ897783 \\
\hline Thyronectria concentrica (Mont. \& Fr.) Voglmayr \& Jaklitsch & CBS 47469 & KM231080 & KM231835 & KM232408 \\
\hline
\end{tabular}

${ }^{a}$ Numbers in bold indicate the newly provided sequences.

\section{DNA extraction, PCR amplification and sequencing}

The genomic DNA was extracted from fresh mycelium following the methods of Wang and Zhuang (2004). Three primer pairs, acl1-230up/acl1-1220low (Gräfenhan et al. 2011), ITS5/ITS4 (White et al. 1990) and fRPB2-5F/fRPB2-7cR (Liu et al. 1999) were used to amplify the sequences or partial sequences of the larger subunit of the ATP citrate lyase (ACL1), the internal transcribed spacers with the $5.8 \mathrm{~S}$ nuclear ribosomal DNA (ITS) and the second largest subunit of the RNA polymerase II (RPB2), respectively. PCR reactions were performed on an ABI 2720 Thermal Cycler (Applied Biosciences, Foster City, California, USA), based on the procedures detailed in Gräfenhan et al. (2011), White et al. (1990) and Liu et al. (1999). DNA sequencing was carried out in both directions on an ABI 3730XL DNA Sequencer (Applied Biosciences). 


\section{Sequence alignment and phylogenetic analyses}

Newly generated sequences and those retrieved from GenBank are listed in Table 1. Nalanthamala psidii (Sawada \& Kuros.) Schroers \& M.J. Wingf. and Thyronectria concentrica (Mont. \& Fr.) Voglmayr \& Jaklitsch were used as outgroup taxa. Sequences were assembled, aligned and the primer sequences were trimmed with BioEdit 7.0.5 (Hall 1999) and converted to NEXUS files by ClustalX 1.8 (Thompson et al. 1997). The partition homogeneity test of ACL1, ITS and RPB2 regions was performed with PAUP 4.0b10 (Swofford 2002). To confirm the phylogenetic positions of the new species, sequences of ACL1, ITS and RPB2 were combined and analysed with Bayesian Inference (BI) and Maximum Parsimony (MP) analyses. The MP analysis was performed with PAUP 4.0b10 (Swofford 2002) using 1000 replicates of heuristic search with random addition of sequences and subsequent TBR (tree bisection and reconnection) branch swapping. Topological confidence of resulted trees was tested by maximum parsimony bootstrap proportion (MPBP) with 1000 replications, each with 10 replicates of random addition of taxa. The BI analysis was conducted by MrBayes 3.1.2 (Ronquist and Huelsenbeck 2003) using a Markov chain Monte Carlo algorithm. Nucleotide substitution models were determined by MrModeltest 2.3 (Nylander 2004). GTR+I+G was shown to be the best-fit model for the combined sequences in the BI analysis. Four Markov chains were run simultaneously for 1,000,000 generations with the trees sampled every 100 generations. A 50\% majority rule consensus tree was computed after excluding the first 2500 trees as 'burn-in'. Bayesian inference posterior probability (BIPP) was determined from the remaining trees. Trees were examined in TreeView 1.6.6 (Page 1996). BIPP greater than $90 \%$ and MPBP greater than $50 \%$ are shown at the nodes.

\section{Results}

\section{Sequence comparison and phylogenetic inference}

The ACL1, ITS and RPB2 sequences of 25 taxa belonging to 10 genera having fusarium-like asexual states were analysed through the methods of BI and MP. The PHT $(\mathrm{P}=0.01)$ indicated that the individual partitions were not highly incongruent (Cunningham 1997); the three loci were thus combined for phylogenetic analyses. The combined datasets include 2258 characters, of which 1085 were constant, 173 variable and parsimony-uninformative and 1000 parsimony-informative. The $\mathrm{MP}$ analysis resulted in a single most parsimonious tree (tree length $=4885, \mathrm{CI}=$ $0.4491, \mathrm{HI}=0.5509, \mathrm{RI}=0.5638, \mathrm{RCI}=0.2532$ ). The final matrix was deposited in TreeBASE with accession No. S20853. The BI tree generated is shown (Figure 1). The topology of the BI tree is similar to that of the MP tree. The 25 investigated species were grouped together $(\mathrm{BIPP} / \mathrm{MPBP}=100 \% / 96 \%)$ and further segregated into two main clades (Figure 1). Species of Geejayessia clustered into one clade together 


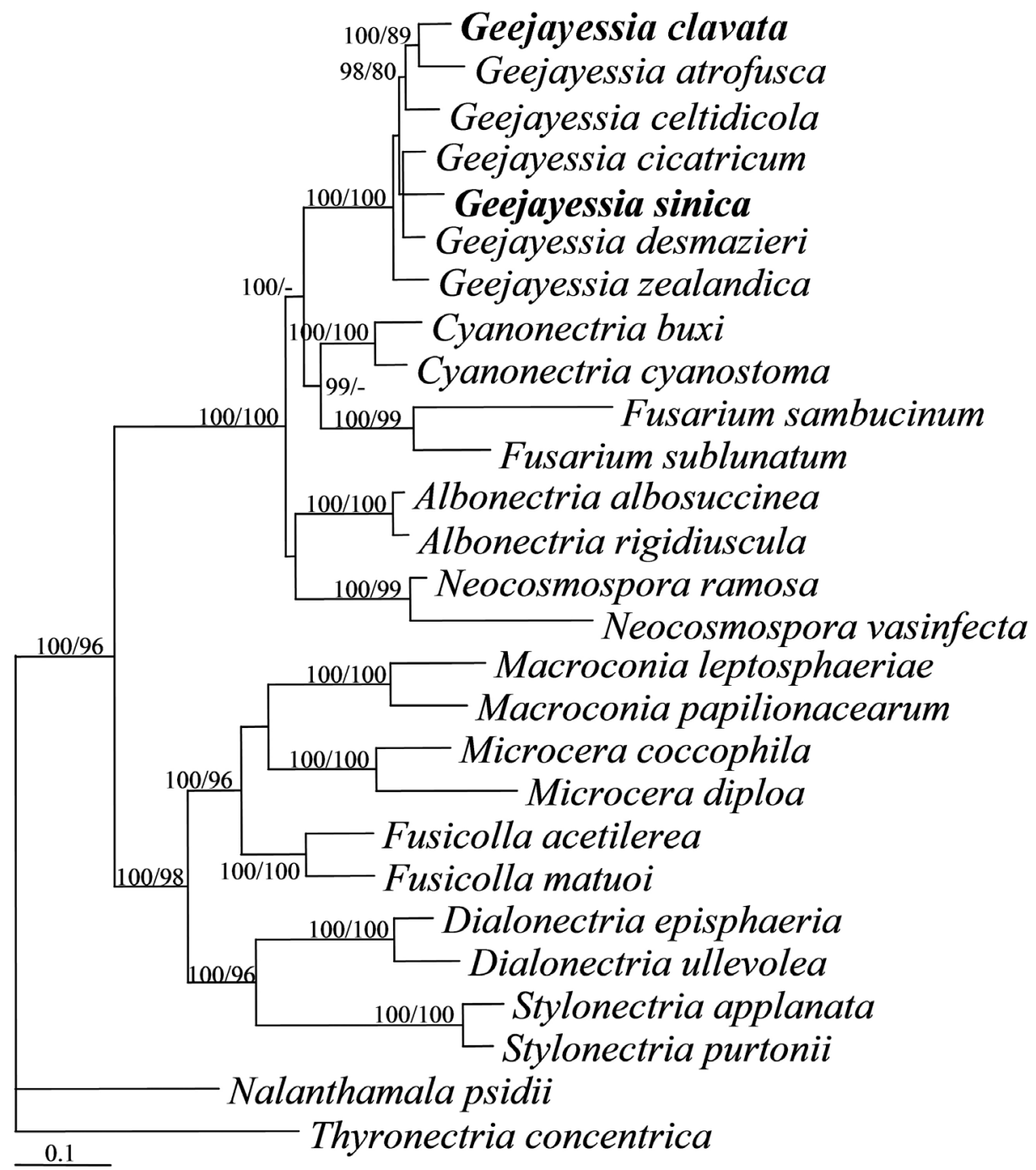

Figure I. A Bayesian Inference trees inferred from the combined ACL1, ITS and RPB2 sequences. BIPP (left) above $90 \%$ and MPBP (right) above $50 \%$ are indicated at nodes.

with Albonectria Rossman \& Samuels, Cyanonectria Samuels \& P. Chaverri, Fusarium and Neocosmospora E.F. Sm. (BIPP/MPBP $=100 \% / 100 \%)$ and those of Dialonectria (Sacc.) Cooke, Fusicolla Bonord., Macroconia (Wollenw.) Gräfenhan, Seifert \& Schroers, Microcera Desm. and Stylonectria Höhn. formed another clade (BIPP/MPBP = 100\%/98\%). HMAS 248725, HMAS 248726 and other representatives of Geejayessia formed a highly supported monophyletic group (BIPP/MPBP $=100 \% / 100 \%)$, which confirmed their taxonomic positions in the genus. 


\section{Taxonomy}

\section{Geejayessia clavata Z.Q. Zeng \& W.Y. Zhuang, sp. nov.} Fungal Names: FN570429

Figures 2, 3

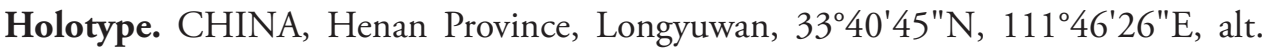
1500 m, on bark of Buxus sp., 17 September 2013, H.D. Zheng, Z.Q. Zeng \& Z.X. Zhu 8728 (holotype: HMAS 275654), dried ex-type culture HMAS 248725.

Etymology. The specific epithet refers to the clavate microconidia.

Description. Mycelium not visible around ascomata or on host. Ascomata perithecial, crowded in group of 5 to 40, on basal stroma, oval, subglobose to globose,

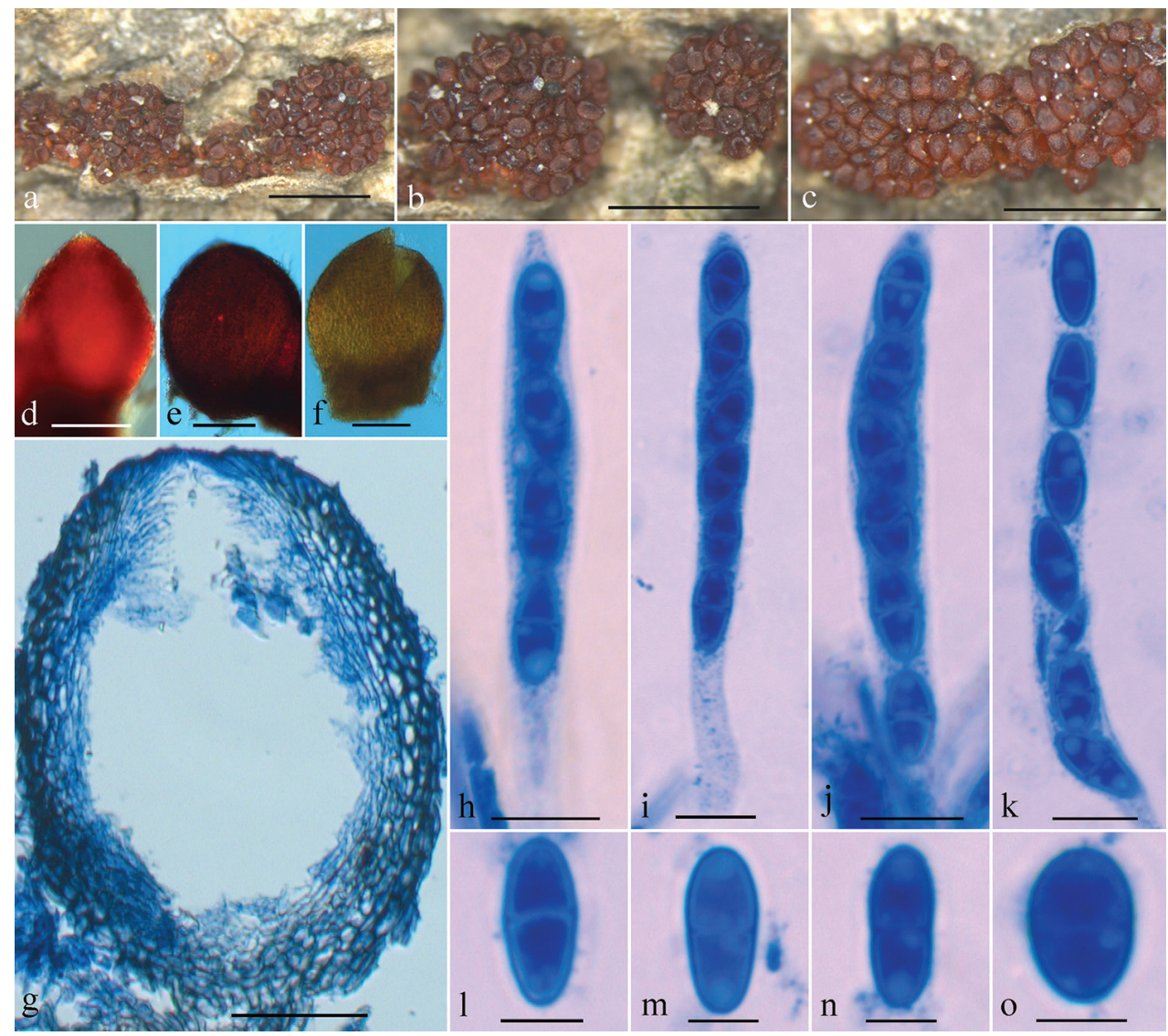

Figure 2. Geejayessia clavata sexual state (holotype, HMAS 275654): a-c Ascomata on natural substrate d-f colour of perithecium in water (d), $3 \% \mathrm{KOH}(\mathbf{e})$ and $100 \%$ lactic acid (f) $\mathbf{g}$ median section through perithecium h-k Asci with ascospores I-o Ascospores. Scale bars: $1 \mathrm{~mm}(\mathbf{a}-\mathbf{c}) ; 100 \mu \mathrm{m}(\mathbf{d}-\mathbf{f}) ; 50 \mu \mathrm{m}(\mathbf{g})$; $10 \mu \mathrm{m}(\mathbf{h}-\mathbf{k}), 5 \mu \mathrm{m}(\mathbf{l}-\mathbf{o})$. 

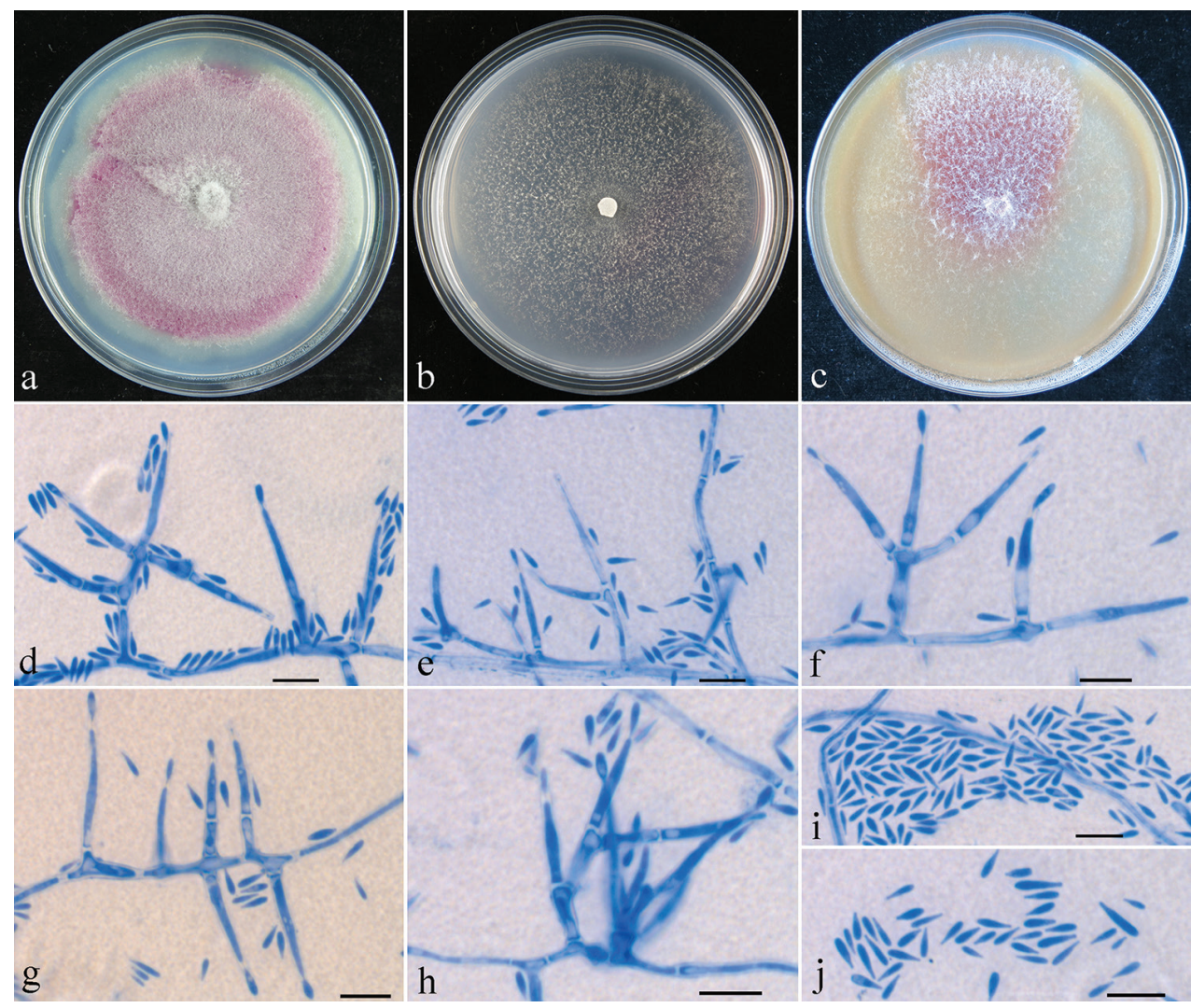

Figure 3. Geejayessia clavata asexual state (HMAS 248725): a-c colony on PDA (a) SNA (b) and CMD (c) $\mathbf{d}-\mathbf{j}$ conidiophores, phialides and/or microconidia on SNA. Scale bar: $10 \mu \mathrm{m}(\mathbf{d}-\mathbf{j})$.

smooth, bright red when fresh, red brownish to dark red when dry, with a darker red ostiolar region, turning purple red in $\mathrm{KOH}$ and orange yellow in LA, 128-175 x 206-255 $\mu \mathrm{m}(\mathrm{n}=17)$. Perithecial wall consisting of a single layer, 15-25 $\mu \mathrm{m}$ thick, cells forming textura prismatica, 2-12 $\times 2-6 \mu \mathrm{m}$, walls $1-1.2 \mu \mathrm{m}$ thick. Asci cylindrical, with a rounded apex, (4-7-)8-spored, 55-75 × 5-9 $\mu \mathrm{m}$. Ascospores ellipsoidal to broadly ellipsoidal, equally 2-celled, slightly constricted at septum, smooth or finely verruculose, hyaline or pale brown, obliquely uniseriate in ascus often with ends overlapping, 7.5-12 × 4.5-5.5 $\mu \mathrm{m}$.

Culture characteristics. Colony on PDA $48 \mathrm{~mm}$ diam. after $7 \mathrm{~d}$ at $25^{\circ} \mathrm{C}$, surface cottony, aerial mycelium white, producing vinaceous pigment in medium. Colony on SNA $30 \mathrm{~mm}$ diam. after $7 \mathrm{~d}$ at $25^{\circ} \mathrm{C}$, surface slightly floccose, with sparse whitish aerial mycelium. Colony on CMD $56 \mathrm{~mm}$ diam. after $7 \mathrm{~d}$ at $25^{\circ} \mathrm{C}$, surface floccose, with sparse whitish aerial mycelium, producing vinaceous pigment in medium. Conidiophores with short simple branches. Conidiogenous cells monophialidic, cylindrical, tapering toward the tip, $12-63 \times 1.5-3.5 \mu \mathrm{m}$. Conidia clavate, not in chains, hyaline, aseptate, $4-7 \times 0.8-2 \mu \mathrm{m}(\mathrm{n}=60)$. Macroconidia and chlamydospores not observed. 
Notes. Attempts were made to obtain macroconidia of the fungus in culture, but failed. Although the falcate macroconidia are lacking, the major phenotypic features of the fungus, such as occurrence on bark of Buxus sp., perithecia broadly ampulliform with a short neck, asci cylindrical with a rounded apex, ellipsoidal ascospores uniseptate and conidiophores monophialidic, fit well with the generic concept of Geejayessia. The molecular data confirm the taxonomic placement and indicate its close relationship with $G$. atrofusca (Figure 1, BIPP/MPBP =100\%/89\%). Geejayessia atrofusca differs significantly in dark brown to black ascomata that do not change colour in $\mathrm{KOH}$ or LA, wider asci [(7.5-)9.8-13.3(-15) $\mu \mathrm{m}$ wide] and longer ascospores [(10-)11.2$14.2(-17.0) \mu \mathrm{m}$ long]. Its microconidia are oblong to slightly curved and falcate but not clavate and are longer and wider (Samuels and Rogerson 1984).

\section{Geejayessia sinica Z.Q. Zeng \& W.Y. Zhuang, sp. nov.}

Fungal Names: FN570430

Figures 4, 5

Type. CHINA, Hubei Province, Shennongjia, 31 $29^{\prime} 17^{\prime \prime}$, $110^{\circ} 20^{\prime} 58^{\prime \prime E}$, alt. 2800 m, on bark of Buxus sp., 15 September 2014, Z.Q. Zeng, H.D. Zheng, W.T. Qin \& K. Chen 9606 (holotype: HMAS 254520), dried ex-type culture HMAS 248726.

Etymology. Specific epithet refers to the type locality China.

Description. Mycelium not visible around ascomata or on host. Ascomata perithecial, solitary or in groups of 5 to 40 , with a basal stroma, pyriform or subglobose to globose, smooth, collapsing laterally when dry, red to bright red with a dark red ostiolar region, turning dark purple red in $\mathrm{KOH}$ and light yellow in LA, 255-343 x 176-314 $\mu \mathrm{m}(\mathrm{n}=14)$. Perithecial wall of a single layer, $18-38 \mu \mathrm{m}$ thick, of textura prismatica, cells $8-23 \times 2-6 \mu \mathrm{m}$, walls $1.2-1.5 \mu \mathrm{m}$ thick. Asci subcylindrical to clavate, with a rounded apex, 6(-8)-spored, 88-123 × 7-10(-12.5) $\mu \mathrm{m}$. Ascospores ellipsoidal, hyaline or pale brown, smooth or finely warted, bicellular, slightly constricted at septum, obliquely uniseriate, $10-18(-20) \times 5-7.5 \mu \mathrm{m}$.

Culture characteristics. Colony on PDA $42 \mathrm{~mm}$ diam. after $7 \mathrm{~d}$ at $25^{\circ} \mathrm{C}$, surface cottony, with whitish aerial mycelium, forming concentric rings, with pale vinaceous pigment produced in medium. Colony on SNA $26 \mathrm{~mm}$ diam. after $7 \mathrm{~d}$ at $25^{\circ} \mathrm{C}$, surface slightly velvet, with sparse whitish aerial mycelium. Colony on CMD $40 \mathrm{~mm}$ diam. after $7 \mathrm{~d}$ at $25^{\circ} \mathrm{C}$, surface radial, slightly floccose, with sparse whitish aerial mycelium. Conidiophores with short simple branches. Conidiogenous cells monophialidic, cylindrical, slightly tapering toward the tip, indefinite in length. Macroconidia falcate, with an arcuate tip and a pedicellate foot cell, hyaline, (3-4-)5-septate, 3-septate: $30-53 \times 4-5 \mu \mathrm{m}$, 4-septate: 50-60 × 4.5-5.2 $\mu \mathrm{m}, 5$-septate: 53-80 × 4.6-5.3 $\mu \mathrm{m}$. Microconidia and chlamydospores not observed.

Notes. Geejayessia sinica is phylogenetically related to and morphologically similar to $G$. cicatricum and $G$. desmazieri in perithecial gross morphology, subcylindrical to 


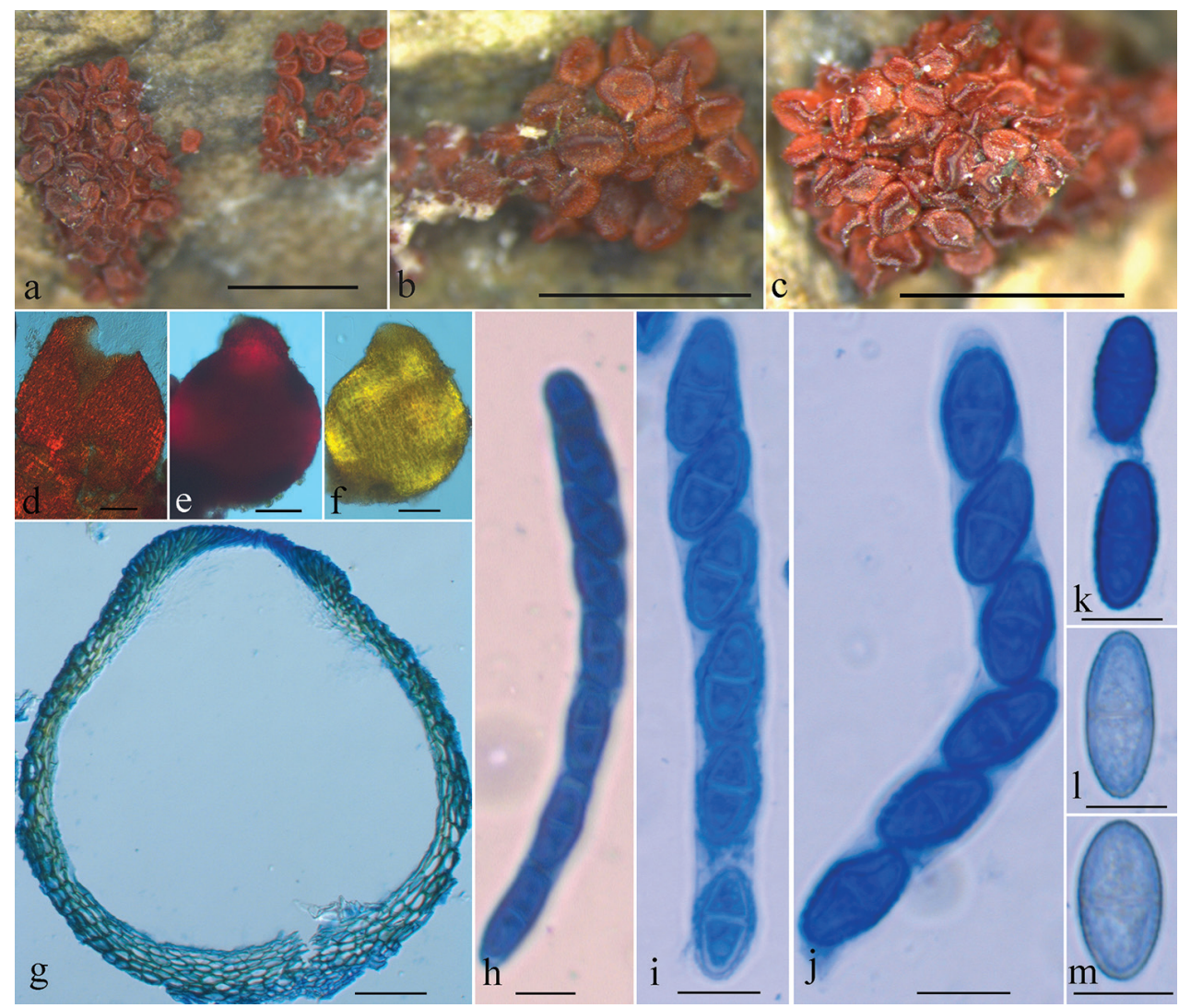

Figure 4. Geejayessia sinica sexual state (holotype, HMAS 254520): a-c ascomata on natural substrate $\mathbf{d}-\mathbf{f}$ colour of perithecium in water (d), $3 \% \mathrm{KOH}(\mathbf{e})$ and $100 \%$ lactic acid (f) $\mathbf{g}$ median section through perithecium $\mathbf{h}-\mathbf{j}$ asci with ascospores $\mathbf{k}-\mathbf{m}$ ascospores. Scale bars: $1 \mathrm{~mm}(\mathbf{a}-\mathbf{c}) ; 100 \mu \mathrm{m}(\mathbf{d}-\mathbf{f})$; $50 \mu \mathrm{m}(\mathbf{g}) ; 10 \mu \mathrm{m}(\mathbf{h}-\mathbf{m})$.

clavate asci, ellipsoidal to broadly ellipsoidal, uniseptate ascospores, falcate macroconidia (Schroers et al. 2011). Geejayessia cicatricum differs from G. sinica in having smaller perithecia $(160-260 \times 125-250 \mu \mathrm{m})$ and ascospores $[(9.5-) 11.5-13(-14.5) \times$ $(4.5-) 5.0-6(-6.5) \mu \mathrm{m}]$, thinner perithecial wall $[(12-) 13.5-18(-21) \mu \mathrm{m}$ thick), shorter asci $[(65.5-) 73-92.5(-103) \mu \mathrm{m}$ long $)$, macroconidia with more septa $[(2-) 5-7(-8)]$ and slow growth on PDA (15-20 mm diam. after $7 \mathrm{~d}$ at $\left.25^{\circ} \mathrm{C}\right)$ (Schroers et al. 2011). Geejayessia desmazieri is distinguished by shorter asci [(75.5-)85(-100) $\mu \mathrm{m}$ long], smaller ascospores [(9.5-)11-12.5(-15) $\times(4.5-) 5.5-6(-7) \mu \mathrm{m}]$ and slow growth on PDA (20 mm diam. after $7 \mathrm{~d}$ at $\left.25^{\circ} \mathrm{C}\right)($ Schroers et al. 2011). The ITS sequence of G. sinica differs from that of the other two species by $29 \mathrm{bp}$ and 29 bp divergences in total length of $521 \mathrm{bp}$. The protein-encoding gene sequences of $G$. sinica differ from those of $G$. cicatricum ( $G$. desmazieri) by 59 (66) bp differences of 815 bp long ACL1 fragment and 34 (35) bp differences of the 672 bp long RPB2 region. 

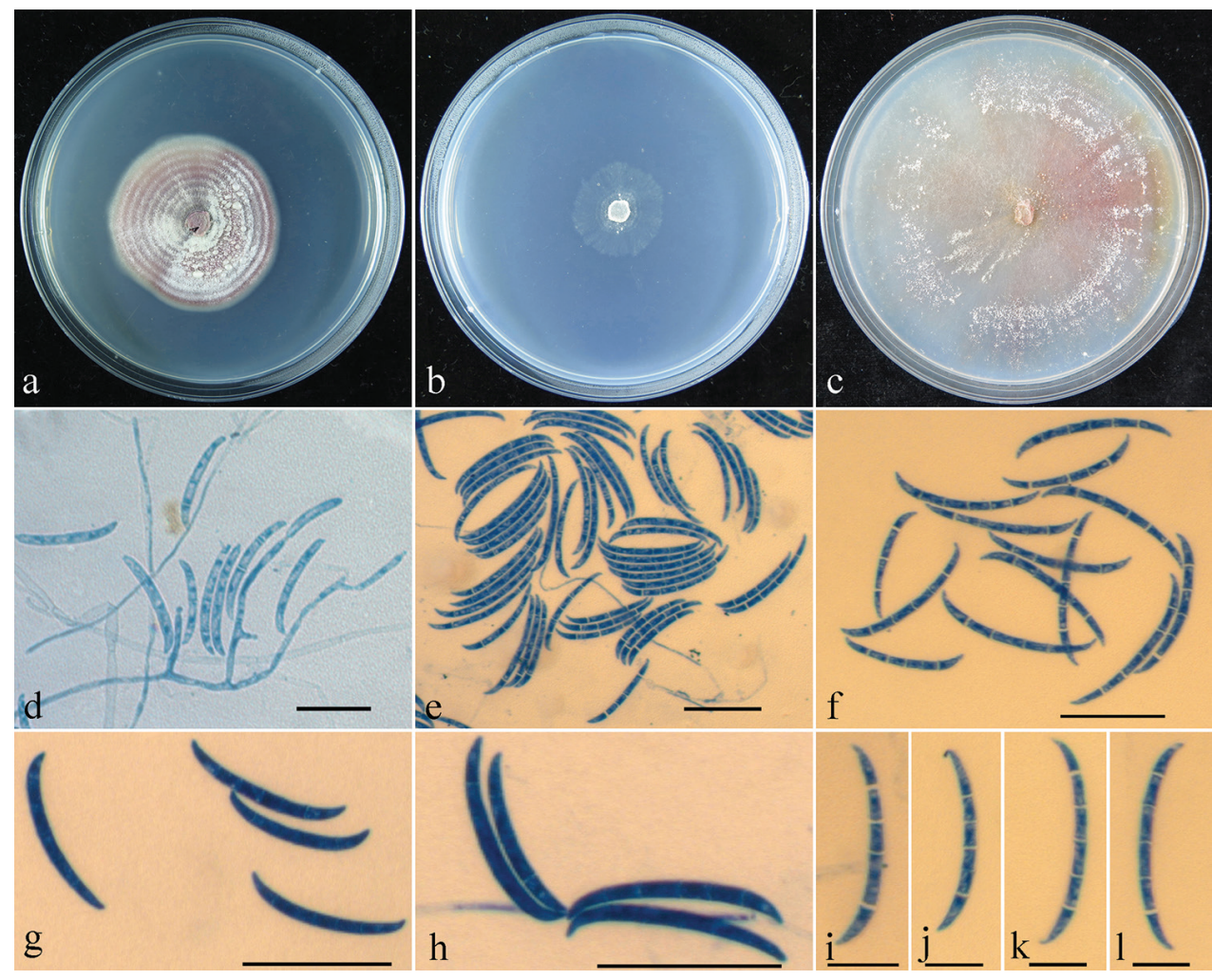

g

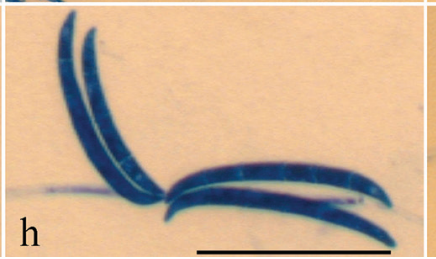

Figure 5. Geejayessia sinica asexual state (HMAS 248726): a-c colony on PDA (a), SNA (b) and CMD (c) d conidiophores, conidiogenous cells and macroconidia on SNA e-I Macroconidia on SNA. Scale bars: $50 \mu \mathrm{m}(\mathbf{d}-\mathbf{h}) ; 10 \mu \mathrm{m}(\mathbf{i}-\mathbf{I})$.

\section{Discussion}

Schroers et al. (2011) recognised five species of Geejayessia. Geejayessia montana Lechat $\& \mathrm{~J}$. Fourn was recently described and its placement was supported by morphological characteristics of both sexual and asexual states, as well as analysis of ITS sequences (Lechat and Fournier 2017). Meanwhile, a new combination, G. hispanica (Lechat \& Priou) Lechat \& J. Fourn was proposed based on the ITS sequence of Geejayessia sp. BRFM 1015 (GenBank accession no. JX082350) (Lechat and Fournier 2017). However, 'Geejayessia hispanica' grows on Phoenix canariensis rather than Buxus, Celtis or Staphylea, which deviates from the original generic concept of the genus (Schroers et al. 2011). This fungus was treated as Cosmospora hispanica Lechat $\&$ Priou in the present study. Cosmospora matuoi Hosoya \& Tubaki was also combined with Geejayessia as $G$. matuoi (Hosoya \& Tubaki) Lechat \& Rossman (Lechat and Rossman 2017). Nevertheless, Gräfenhan et al. (2011) and Lombard et al. (2015) treated Cosmospora matuoi as a member of Fusicolla, which is followed in this study. To clarify the taxonomic positions of ' $G$. hispanica' and ' $G$. matuoi', more evidence is certainly required. 
According to the International Code of Nomenclature for algae, fungi and plants (McNeill et al. 2012), the name Fusarium is accepted as the correct generic name for fungi with Gibberella Sacc. sexual states (Rossman et al. 2013). The asexual states of other genera are marked as fusarium-like (Lombard et al. 2015). In the present study, the phylogeny, based on analyses of the combined ACL1, ITS and RPB2 sequences, recognised nine clades amongst the investigated taxa which are in accordance with the genera Albonectria, Cyanonectria, Dialonectria, Fusicolla, Geejayessia, Macroconia, Microcera, Neocosmospora and Stylonectria. This result is basically consistent with that by Schroers et al. (2011).

Joining the two new species to the Geejayessia clade, the tree topology (Figure 1) remains basically the same as that revealed by Schroers et al. (2011). Our result showed G. clavata and $G$. atrofusca both forming microconidia in culture, grouped together with relatively high statistical supports (Figure 1, BIPP/MPBP $=100 \% / 89 \%$ ). Geejayessia sinica, G. cicatricum and $G$. desmazieri, as sister-groups, are poorly supported (BIPP/MPBP less than 50\%).

Host specificity has been shown in some fungi of Nectriaceae; for example, Thyronectria aurigera (Berk. \& Ravenel) Jaklitsch \& Voglmayr occurs only on Oleaceae, $T$. berolinensis (Sacc.) Seaver on Ribes and T. aquifolii (Fr.) Jaklitsch \& Voglmayr on Ilex aquifolium (Jaklitsch and Voglmayr 2014; Zeng and Zhuang 2016). Species of Geejayessia are also host-specific. As known currently, G. clavata, G. sinica, G. cicatricum and $G$. desmazieri occur only on Buxus spp., G. celtidicola only on Celtis occidentalis and G. atrofusca only on Staphylea trifolia (Schroers et al. 2011).

The genus Geejayessia was previously known from Europe, North America and Oceania (Samuels and Rogerson 1984; Nirenberg and Samuels 2000; Schroers et al. 2011). The new species discovered from central China extends the distribution of the genus to Asia.

\section{Acknowledgements}

We are very grateful to Drs. H.D. Zheng, Z.X. Zhu, W.T. Qin and K. Chen for collecting specimens jointly for this study and to Dr. X.C. Wang for technical help. This work was supported by the National Key Research and Development Program of China (no. 2017YFD0200600), the National Natural Science Foundation of China (no. 31750001) and Frontier Key Program of Chinese Academy of Sciences (no. QYZDY-SSW-SMC029).

\section{References}

Booth C (1959) Studies of pyrenomycetes: IV. Nectria (part I). Mycological Papers 73:1-115. Cunningham CW (1997) Can three incongruence tests predict when data should be combined? Molecular Biology and Evolution 14: 733-740. https://doi.org/10.1093/oxfordjournals.molbev.a025813 
Gräfenhan T, Schroers HJ, Nirenberg HI, Seifert KA (2011) An overview of the taxonomy, phylogeny and typification of nectriaceous fungi in Cosmospora, Acremonium, Fusarium, Stilbella and Volutella. Studies in Mycology 68: 79-113. https://doi.org/10.3114/ sim.2011.68.04

Hall TA (1999) Bioedit: a user-friendly biological sequences alignment editor analysis program for windows 95/98/ NT. Nucleic Acids Symposium Series 41: 95-98.

Hyde KD, Nilsson RH, Alias SA, Ariyawansa HA, Blair JE, Cai L, de Cock AWAM, Dissanayake AJ, Glockling, SL, Goonasekara ID, Gorczak M, Hahn M, Jayawardena RS, van Kan JAL, Laurence MH, Levesque CA, Li XH, Liu JK, Maharachchikumbura SSN, Manamgoda DS, Martin FN, McKenzie EHC, McTaggart AR, Mortimer PE, Nair PVR, Pawlowska J, Rintoul TL, Shivas RG, Spies CFJ, Summerell BA, Taylor PWJ, Terhem RB, Udayanga D, Vaghefi N, Walther G, Wilk M, Wrzosek M, Xu, JC, Yan, JY, Zhou, N (2014) One stop shop: backbones trees for important phytopathogenic genera: I. Fungal Diversity 67(1): 21-125. https://doi.org/10.1007/s13225-014-0298-1

Jaklitsch WM, Voglmayr H (2014) Persistent hamathecial threads in the Nectriaceae, Hypocreales: Thyronectria revisited and re-instated. Persoonia 33: 182-211. https://doi. org/10.3767/003158514X685211

Lechat C, Fournier J (2017) Geejayessia montana (Hypocreales, Nectriaceae), a new species from French Alps and Spain. Ascomycete.org 9(6): 209-213. https://doi.org/10.25664/art-0213 Lechat C, Rossman A (2017) A new species of Fusicolla (Hypocreales), F. ossicola, from Belgium. Ascomycete.org 9(6): 225-228. https://doi.org/10.25664/art-0215

Liu YJ, Whelen S, Hall BD (1999) Phylogenetic relationships among Ascomycetes: evidence from an RNA Polymerase II Subunit. Molecular Biology and Evolution 16:1799-1808. https://doi.org/10.1093/oxfordjournals.molbev.a026092

Lombard L, van der Merwe NA, Groenewald JZ, Crous PW (2015) Generic concepts in Nectriaceae. Studies in Mycology 80: 189-245. https://doi.org/10.1016/j.simyco.2014.12.002

Luo J, Zhuang WY (2010) Three new species of Neonectria (Nectriaceae, Hypocreales) with notes on their phylogenetic positions. Mycologia 102: 142-152. https://doi.org/10.3852/08-224

McNeill J, Barrie FR, Buck WR, Demoulin V, Greuter W, Hawksworth DL, Herendeen PS, Knapp S, Marhold K, Prado J, Prud'homme Van Reine WF, Smith GF, Wiersema JH, Turland NJ (2012) International Code of Nomenclature for Algae, Fungi and Plants (Melbourne Code). Regnum Vegetabile 154: 1-240.

Nirenberg HI (1976) Studies on the morphologic and biologic differentiation in Fusarium section Liseola. Mitteilungen aus der Biologischen Bundesanstalt für Land- und Forstwirtschaft 169: 1-117.

Nirenberg HI, Samuels GJ (2000) Nectria and Fusarium. II. Cosmospora zealandica comb.nov. and its anamorph, Fusarium zealandicum sp. nov. Canadian Journal of Botany 78: 14821487. https://doi.org/10.1139/b00-127

Nylander JAA (2004) MrModeltest v2. Program distributed by the author. Evolutionary Biology Centre, Uppsala University.

Page RD (1996) TreeView: An application to display phylogenetic trees on personal computers. Computer Applications in the Biosciences 12: 357-358. 
Ronquist F, Huelsenbeck JP (2003) MrBayes 3: Bayesian phylogenetic inference under mixed models. Bioinformatics 19: 1572-1574.

Rossman AY, Seifert KA, Samuel GJ, Minnis AM, Schroers HJ, Lombard L, Crous PW, Póldma K, Cannon PF, Summerbel RC, Geiser DM, Zhuang WY, Hirooka Y, Herrera C, SalgadoSalazar C, Chaverri P (2013) Genera in Bionectriaceae, Hypocreaceae, and Nectriaceae (Hypocreales) proposed for acceptance or rejection. IMA Fungus 4: 41-51. https://doi. org/10.5598/imafungus.2013.04.01.05

Samuels GJ, Rogerson CT (1984) Nectria atrofusca and its anamorph, Fusarium staphyleae, a parasite of Staphylea trifolia in Eastern North America. Brittonia 36: 81-85. https://doi. org/10.2307/2806300

Schroers HJ, Gräfenhan T, Nirenberg HI, Seifert KA (2011) A revision of Cyanonectria and Geejayessia gen. nov., and related species with Fusarium-like anamorphs. Studies in Mycology 68: 115-138. https://doi.org/10.3114/sim.2011.68.05

Summerbell RC, Schroers HJ (2002) Analysis of phylogenetic relationship of Cylindrocarpon lichenicola and Acremonium falciforme to the Fusarium solani species complex and a review of similarities in the spectrum of opportunistic infections caused by these fungi. Journal of Clinical Microbiology 40: 2866-2875. https://doi.org/10.1128/JCM.40.8.28662875.2002

Swofford D (2002) PAUP*: Phylogenetic Analysis using Parsimony (*and other methods). version $4 \mathrm{~b} 10$. Sinauer Associates, Sunderland, Massachusetts.

Thompson JD, Gibson TJ, Plewniak F, Jeanmougin F, Higgins DG (1997) The CLUSTAL_X windows interface: flexible strategies for multiple sequence alignment aided by quality analysis tools. Nucleic Acids Research 25: 4876-4882. https://doi.org/10.1093/ nar/25.24.4876

Wang L, Zhuang WY (2004) Designing primer sets for amplification of partial calmodulin genes from penicillia. Mycosystema 23(4): 466-473.

White TJ, Bruns T, Lee S, Taylor J (1990) Amplification and direct sequencing of fungal ribosomal RNA genes for phylogenetics. In: Innis MA, Gelfland DH, Sninsky JJ, White TJ (Eds) PCR protocols: a guide to methods and applications. Academic, San Diego, 315322. https://doi.org/10.1016/B978-0-12-372180-8.50042-1

Zeng ZQ, Zhuang WY (2016) Revision of the genus Thyronectria (Hypocreales) from China. Mycologia 108(6): 1130-1140. https://doi.org/10.3852/16-004 